\title{
Efficiency of Chinese Real Estate Market Based on Complexity-Entropy Binary Causal Plane Method
}

\author{
Yan Chen, ${ }^{1}$ Ya Cai, ${ }^{2}$ and Chengli Zheng $\mathbb{D}^{2}$ \\ ${ }^{1}$ School of Mathematics and Statistics, Central China Normal University, Wuhan 430079, China \\ ${ }^{2}$ School of Economics and Business Administration, Financial Engineering Research Center, Central China Normal University, \\ Wuhan 430079, China \\ Correspondence should be addressed to Chengli Zheng; zhengchengli168@163.com
}

Received 30 October 2019; Accepted 24 December 2019; Published 13 January 2020

Guest Editor: Marco Locurcio

Copyright (c) 2020 Yan Chen et al. This is an open access article distributed under the Creative Commons Attribution License, which permits unrestricted use, distribution, and reproduction in any medium, provided the original work is properly cited.

Real estate market is a complex system. A rational real estate market is not only helpful to people's living standards but also beneficial to countries' macroeconomic stability. Is Chinese real estate market rational? This paper attempts to study the efficiency of Chinese real estate market by using the complexity-entropy binary causal plane method. We firstly discuss the formation mechanism of real estate price, which provides a theoretical basis for testing the efficiency, and compute the real estate market efficiency of 70 main Chinese cities. The results show that neither the whole market nor the main cities have reached the weak efficiency, and the efficiency and complexity of each city are different, and the relationship between them is significantly negative. In addition, this paper also compares the efficiency and complexity of Chinese real estate market with American real estate market. Then, some suggestions for the healthy development of Chinese real estate market in the future are put forward.

\section{Introduction}

In July 1998, the notice of the State Council on further deepening the reform of the housing system and accelerating the housing construction was issued, which clearly put forward the reform goal of developing the housing trading market and accelerating the housing construction. Since then, the welfare housing system traversing nearly 40 years has been withdrawn from the historical stage. "Marketization" has become the new theme of the real estate system. Real estate began to appear as a commodity. From then on, real estate is not only an essential element to satisfy the basic residential attribute of residents but also an indispensable part of family property. Nowadays, real estate is not only a commodity but also an asset. With the development of financial industry, real estate has gradually become a major tool for investment and speculation. At the same time, the market size of real estate has gradually become larger and larger. By 2018, the added value of real estate industry has accounted for nearly $7 \%$ of GDP, while the contribution of real estate and its related industries to Chinese GDP has reached about $1 / 3$. It can be said that Chinese real estate has achieved great success in development size and speed after nearly 20 years of continuous reform and exploration. At the same time, the real estate has played a significant role in pushing the progress of other industries related to itself, dramatically promoting the rapid development of the national economy.

However, Chinese real estate price has kept increasing rapidly in recent years. Subsequently, the ratio of housing price to income is seriously unbalanced, and the house price bubble accumulates gradually. It can be seen that this abnormal high-speed rising trend has brought many potential problems. On the one hand, the imbalance of superficial demand and supply caused by the rapid rise of house prices will lead to an overheated economy and lead to housing price bubble, which has a significant crowding out effect on the real economy. Once this rapid growth cannot continue, the bubble will collapse and then result in the slump in the overall economy. More seriously, it will push the economy into depression, for instance, the subprime crisis caused by the breakdown of real estate market in America in 2007. That 
crisis was a financial-market mess, as well as a housing one. On the other hand, the rapid rise of housing price or irrational housing price will lead to a dramatic decline in the housing consumption level of most ordinary people and affect people's living standards. Also, it does harm to the stability of economy and society.

In view of the importance of the reasonable and orderly development of the real estate market, it has become a matter of concern for many scholars to evaluate and quantify the efficiency of the market. Meese and Wallace [1] applied the efficient market theory to the real estate market in San Francisco and found that the real estate market in that region is efficient in the long term, but inefficient in the short term, owing to the deviation caused by the transaction cost between the housing price and fundamental value. However, other scholars believed that it was the existence of market bubbles and irrational expectations, both of which led to this bias and further led to the inefficient market, such as Clayton's [2] continuous rational housing price model. The analysis about housing price efficiency varies from the angle of study. Case and Shiller [3] proposed a new method to examine the applicability of "Efficient Market Hypothesis" in real estate market in different American cities by using excess return rate. They argued that the reason for housing inefficiency was because the interest rate was not correctly estimated. Abraham and Hendershott [4] used the economic fundamental information to measure the efficiency of real estate market in 30 cities of the United States and calculated the deviation degree between the fundamental price and the actual housing price. They finally thought this deviation as the bubble of housing price. Grenadier [5] studied this issue from the perspective of vacancy rate. He attributed the inefficiency of the real estate market to the high vacancy rate, which was caused by monopoly. Kunzel [6] made a more comprehensive analysis of the efficiency of real estate market and proposed that the inefficiency of housing price originated from several reasons: space restriction, long construction period, transaction cost, speculation, and so on.

Domestic scholars' research on this problem is relatively behind. Wang et al. [7] applied the sequence correlation method to test whether the housing price index of China 1998-2004 conformed to the random walk model and obtained a negative conclusion, that is, the real estate market of China had not yet reached weak form efficiency. In addition to the newly constructed houses, the second-hand real estate market is also worth the attention. Xie [8] conducted an empirical test on newly constructed real estate market and the second-hand real estate market in Shanghai by collecting the quarterly data of CFS Shanghai index from 2005 to 2013. The test methods included unit root test and sequence correlation test. The results showed that the efficiency of each market segment in Shanghai was not the same. Among them, the office market and shop market in the new real estate market and the rental real estate market in the secondhand real estate market had reached weak form efficiency, while the real estate market in the new real estate market and the sales real estate market in the second-hand real estate market had not. However, the results of the sequence correlation test showed that the efficiency of each market segment and the overall real estate market in Shanghai failed to achieve weak form.

In order to study the efficiency of Chinese real estate market, this paper first puts forward the theory about the housing price mechanism, which provides a theoretical foundation for testing the efficiency of real estate market and then conducts empirical test with the complexity-entropy binary causal plane method. The results show that the real estate market of 70 main Chinese cities as well as the overall Chinese real estate market does not reach weak form efficiency. The degree of efficiency of each city shows difference and is significantly negatively related to the corresponding degree of complexity. In addition, in order to control housing prices and promote the orderly development of the real estate market more effectively, we further compare the efficiency of real estate market in China with that in America, whose real estate market has also experienced many boom years. Combined with the historical experience in the real estate industry development of two countries, this paper analyzes the reasons that why there are differences in the efficiency of the real estate market between two countries and then puts forward some valuable suggestions for the healthy development of Chinese real estate market in the future.

A novel feature of our study is that we propose a novel method called complexity-entropy binary causal plane method to detect the hidden structure in the housing price and get the efficiency and complexity of real estate market in 67 main cities and overall China. We collect the monthly data of 67 main cities of China during 2005 to 2017. With a wide range of samples and a long period of time, our result can be regarded as representative, so we think there is reference value for cities to implement policies to maintain the stability of housing prices. Moreover, we conduct the comparative study of the efficiency of the real estate market in China and in America. The results provide a direction for learning from foreign advanced management and regulation experience.

The rest of the paper is organized as follows. Section 2 clarifies the theory of housing price mechanism. Section 3 develops the efficiency and complexity measure method based on the complexity-entropy binary causal plane method. Section 4 conducts empirical analysis to demonstrate the efficiency of real estate markets in China and America. Finally, Section 5 concludes our paper.

\section{Theory about Housing Price Mechanism}

Analogous to the efficiency theory of financial market, the efficiency of real estate market can be described as follows: housing price can quickly respond to all kinds of relevant information so that actual housing price is consistent with its intrinsic fundamental value. Therefore, the research on the efficiency of housing price should first clarify the formation mechanism of housing price. The process of how the real estate market price is formed under the principle of noarbitrage pricing is presented as follows.

Suppose that the participants in the real estate market (taking the buyer as an example) at time $t$ have two choices: 
(1) buying a house to live in, where the price is $p_{t}$; (2) renting a house to live in, where the rent is $d_{t}$ per month. Under the condition of short selling, above two cases should be the same, that is,

$$
p_{t}=\sum_{i=1}^{\infty} \frac{E\left(d_{t+i-1} \mid \Pi_{t}\right)}{\left(1+r_{\mathrm{f}}\right)^{i}},
$$

where $r_{\mathrm{f}}$ denotes the risk-free rate. If the right-hand side in equation (1) is not equal to the left-hand side, an arbitrary opportunity will appear. Specifically, if there is $p_{t}<$ $\sum_{i=1}^{\infty}\left(E\left[d_{t+i-1} \mid \Pi_{t}\right]\right) /\left(1+r_{\mathrm{f}}\right)^{i}$, we can make an arbitrage by constructing following portfolio: firstly, borrow money from a bank to buy a house and rent it out at a price of $d_{t}$ per month and then repay the bank loan by installments. It is clear that the investor can make profit easily. We assume that the market participants are rational. They can find this arbitrary opportunity and then perform the same behavior that participants all buy houses to rent them out. In this case, the house price will rise and the rent will decline until equation (1) holds true. After this game, the arbitrary opportunity will disappear and the market reaches no-arbitrage equilibrium. On the contrary, if $p_{t}>\sum_{i=1}^{\infty}\left(E\left[d_{t+i-1} \mid \Pi_{t}\right]\right) /$ $\left(1+r_{\mathrm{f}}\right)^{i}$, the participants can conduct the opposite arbitrage until a new equilibrium appear. However, if the short selling is limited, the price cannot reach equilibrium by arbitrages. There will always exist $p_{t}<\sum_{i=1}^{\infty}\left(E\left[d_{t+i-1} \mid \Pi_{t}\right]\right) /\left(1+r_{\mathrm{f}}\right)^{i}$ or $p_{t}>\sum_{i=1}^{\infty}\left(E\left[d_{t+i-1} \mid \Pi_{t}\right]\right) /\left(1+r_{f}\right)^{i}$. At this time, the actual house price can be described as follows:

$$
p_{t}=\sum_{i=1}^{\infty} \frac{E\left[d_{t+i-1} \mid \Pi_{t}\right]}{\left(1+r_{\mathrm{f}}\right)^{i}}+h_{t}=p_{t}^{*}+h_{t},
$$

where $p_{t}^{*}$ is the basic value of a house and $h_{t}$ denotes the extra price that can contribute to arbitrage.

On the other hand, Pan and Wang [9] analyzed the formation of housing price from a rational perspective. They believed that the actual market price would deviate from the basic price if the market is irrational. Accordingly, there also exists bias between actual house price and its theoretical price in irrational real estate market. This situation yields the following price rules:

$$
p_{t}=p_{t}^{*}+b_{t}
$$

where $b_{t}$ denotes irrational price or house price bubbles, deviating from the basic value [10]. In most cases, $b_{t}>0$. Generally, $b_{t}<0$ will not occur. But it also may appear due to the impact of demand in the actual transaction. In the statistical sense, it should be positive.

Comparing these two price formation mechanisms, $b_{t}$ in formula (3) belongs to the irrational component, while $h_{t}$ in formula (2) belongs to the reasonable component, or at least some of which are reasonable. For the simplification of presentation, we just think $b_{t}$ as a reasonable component and think $h_{t}$ as an irrational component. In this way, after considering the irrational component, we propose that the house price is formed by following components:

$$
p_{t}=p_{t}^{*}+h_{t}+b_{t} \text {. }
$$

The real estate market is efficient when market participants are fully rational. At this time, the irrational component $b_{t}$ does not exist, and the housing price can be characterized by equation (2). From the perspective of market efficiency theory, this means

$$
E\left[b_{t}\right]=0 \text { and } b_{t} \text { follows random walk. }
$$

Then, $b_{t}$ can be expressed as

$$
b_{t}=p_{t}-E\left[p_{t}^{*}+h_{t}\right] .
$$

In this way, we can judge the efficiency of real estate market by testing whether series $b_{t}$ has random walk characteristics.

However, it is not easy to get the basic value $p_{t}^{*}+h_{t}$ of a house. Although $p_{t}^{*}=\sum_{i=1}^{\infty}\left(E\left[d_{t+i-1} \mid \Pi_{t}\right]\right) /\left(1+r_{\mathrm{f}}\right)^{i}$ in theory, future cash flow of yield $d_{t}$ cannot be obtained. Moreover, the computation of $h_{t}$ is more difficult, as a kind of right of resale or convenience yield. Such fact makes it difficult to get the irrational price $b_{t}$ and test the efficiency of markets.

Then, we decide to start with the ratio of house price to income. As the main indicator to measure the purchasing power of housing in a certain period, the ratio of house price to income is also the basic index to evaluate whether the housing market is healthy [11]. In the early 1990s, Andrew Hamer, a World Bank expert, conducted a study on the reform of Chinese housing system and gave a ratio from 4 times to 6 times. This interval is considered as ideal by the World Bank. According to the relevant data published by the United Nations, the dispersion about the ratio of house price to income in different countries is quite large. According to the statistical results of 96 countries in 1998, the ratio of house price to income in these countries ranged from 0.8 to 30 , with an average value of 8.4 and a median value of 6.4 . Chen [12] believes that the ratio of house price to income is reflection of real interest rate and is the most accurate indicator of housing price. In general, the ratio $k_{t}$ of average house price to income of a country or region is usually calculated by

$$
k_{t}=\frac{p_{t}}{I_{t}},
$$

where $p_{t}$ denotes the average price of a house and $I_{t}$ denotes the average annual income of a family. According to the theory about the ratio of house price to income, the housing price and income ratio should be kept within a suitable interval in a reasonable real estate market. Otherwise, it is an unhealthy market, where the house price is always underestimated or overestimated (generally overestimated). In other words, there are irrational components or bubbles in the real estate market. If there is an irrational component, the market is considered to be inefficient.

From a general equilibrium perspective, all the borrowing and lending in a region would offset, only leaving income to support house prices. Therefore, a reasonable housing price should be in proportion to personal income. This viewpoint has been proved by Case and Shiller [13]. They think that there is a stable relationship between 
personal income and housing price if a housing price bubble does not exist. In order to measure the efficiency of the real estate market, we just need to consider whether the rest of housing price that is not fully explained by income is efficient or not, that is, whether it has the characteristics of random walking. In addition, the reasonable ratio of house price to income is basically stable. In other words, it is a constant or $k_{t}=k$. To generalize the model, we add an intercept term, so we can get

$$
p_{t}=a+k E\left[I_{t}\right]+\varepsilon_{t} .
$$

Thus, we have $\varepsilon_{t}=p_{t}-\left(a+k E\left[I_{t}\right]\right)$, and it is a random disturbance term and satisfies $E\left[\varepsilon_{t}\right]=0$. At this time, we can test the efficiency of real estate market by calculating the relevant measures of $\varepsilon_{t}$ with the permutation entropy method.

\section{Efficiency Measure Based on Complex- Entropy Binary Causal Plane Method}

In recent years, system complexity and nonlinear dynamic methods have been paid more attention. Zunino et al. $[14,15]$ pointed out that it can effectively detect the structural information hidden in system noise, even if the system is at the edge of chaos. In the process of empirical test, we use the complexity-entropy binary causal plane method based on $b_{t}$ to detect the hidden structure of real estate market price and then measure its efficiency and complexity. This method, as proposed in the work of Rosso et al. [16], can not only distinguish Gaussian and nonGaussian processes but also demonstrate their correlation degree. Therefore, it is considered to be a good method to test the market efficiency.

3.1. Market Efficiency and Shannon Entropy. Entropy can accurately test the uncertainty and confusion of time series without any additional restrictions on the distribution. If the price follows a pure random walk, then there will not exist correlation relationship between time series, where the entropy of the sequence is the largest and represents a completely disordered state. Otherwise, it is difficult to reach the maximum entropy. It was Gulko [17] who firstly applied entropy to study financial time series by showing that the maximum-entropy formalism, also called informational efficiency, made the efficient market hypothesis operational and testable. If the market is efficient, the time series will satisfy random walk and the normalized entropy is 1 . The smaller the entropy is, the harder the market reaches random walk and the less efficient the market is. Therefore, the normalized entropy (relative maximum entropy) can be applied to measure the real estate market efficiency. There are many proposed concepts of entropy. Matesanz and Ortega [18] proposed Shannon entropy, Renyi entropy, Tsallis entropy, approximation entropy, and so on. Risso [19] pointed out that Shannon entropy is the most widely used entropy in financial market. For a given probability distribution $P=\left\{p_{i}: i=1, \ldots, N\right\}$, Shannon entropy is defined as

$$
S[P]=-\sum_{i=1}^{N} p_{i} \ln p_{i} .
$$

It is clear that when the probability distribution is uniformly distributed, that is, $P_{e}=\{1 / N, \ldots, 1 / N\}$, the Shannon entropy can reach the maximum value, and $S_{\max }=S\left[P_{e}\right]=\ln N$. On the other hand, if there is a deterministic event, the corresponding distribution can be expressed as $P_{0}=\{0, \ldots 1 \ldots, 0\}$, and the value of Shannon entropy is 0 .

3.2. Permutation Entropy. Before calculating the entropy value of a given time series, we generally need to deal with the series to get the corresponding distribution. Rosso et al. [16] found that if the basic probability distribution took the causal relationship between time series into account and then used the above information measure the entropy, the result would be excellent. More importantly, the difference between chaos and randomness can be clearly distinguished. Later, Bandt and Pompe [20] successfully proposed a symbol method based on the reconstruction of phase space, which could introduce such causal relationship into the basic probability distribution. It was suggested by Ridel et al. [21] that this method was the only popular method considering the intertemporal structure of time series so far. It has been used to study the efficiency of crude oil markets [22], foreign exchange markets [23], and stock markets [14]. This method can be summarized as follows:

(1) Given a time series $\left\{x_{t}: t=1, \ldots, M\right\}$. Embedding dimension is $D$, and time delay is $\tau$. The connection between dimension $D$ and new subsequence is represented as follows:

$$
s \longmapsto\left(x_{s-(D-1) \tau}, x_{s-(D-2) \tau}, \ldots, x_{s-\tau}, x_{s}\right) .
$$

We call it the ordinal pattern of embedding dimension $D$. As for any time $s$, there is always a new subsequence mapping to it, which is formed by a vector with dimension $D$ as shown in formula (10). It is easy to notice that the larger dimension can incorporate more historical information.

(2) Each subsequence $i$ is sorted in ascending order. We can obtain a new set related permutation, marking it as $\pi_{i}=\left(r_{0}, r_{1}, \ldots, r_{D-1}\right)_{i}$. The rearranged series is

$$
x_{s-r_{D-1} \tau} \leq x_{s-r_{D-2} \tau} \leq \cdots \leq x_{s-r_{1} \tau} \leq x_{s-r_{0} \tau}
$$

(3) For each dimension, there is $D$ ! kinds of arrangement. The probability distribution of the permutation in these time series is given by

$$
p\left(\pi_{i}\right)=\frac{\#\{s \mid 1+(D-1) \pi \leq s \leq M\}}{M-(D-1) \tau},
$$

where $s$ satisfies formula (10) and \# denotes the number of occurrences of the permutation $\pi$ in the class.

According to above steps, the probability distribution of each ordinal pattern in the time series can be obtained. In 
order to obtain a more accurate distribution, the length of time series $M$ is required to be infinite. So, we can get the corresponding distribution when embedding dimension $D$ and delay time $\tau$ are given. For achieving more reliable statistical results, it is generally suggested $M \gg D$ ! [24]. Bandt and Pompe suggested $3 \leq D \leq 7$ in practical applications. As for the time delay, $\tau=1$ is common. Of course, there are also different selections (for details, see the literature [25]). Some recent applications and development of permutation entropy also can be seen in related literature $[26,27]$.

3.3. Complexity-Entropy Binary Causal Plane Method. In addition to permutation entropy, Lamberti et al. [28] pointed out that statistical complexity measure (SCM) can also be used to measure the efficiency of markets. SCM can not only detect the dynamic details of the system but also distinguish the periodicity and the degree of chaos, which is superior to the entropy measure. Mathematically, SCM is defined as follows:

$$
C_{J S}[P]=Q_{J}\left[P, P_{e}\right] \bullet H_{S}[P],
$$

where $H_{S}[P]$ is normalized Shannon entropy, and it is defined as

$$
H_{s}[P]=\frac{S[P]}{S_{\max }} .
$$

And $Q_{J}\left[P, P_{e}\right]$ is the Jensen-Shannon divergence; it is defined as

$$
Q_{J}\left[P, P_{e}\right]=Q_{0} \bullet J\left[P, P_{e}\right],
$$

where $J\left[P, P_{e}\right]=\left\{S\left[\left(P+P_{e}\right) / 2\right]-S[P] / 2-S\left[P_{e}\right] / 2\right\}$ and $Q_{0}=$ $1 / J\left[P_{0}, P_{e}\right]$.

SCM can describe the structural complexity of a system, which cannot be achieved by entropy just measuring randomness. Different entropy values mean different randomness, but they may have the same SCM value because they have the same complexity. The larger the SCM value is, the more complex the system is. Accordingly, the correlation degree of sequences in the system is higher. We take two simple examples to further illustrate the difference between SCM and entropy. The entropy of linear data is 0 , and the entropy of absolute fair dice game is 1 . However, both their SCMs are 0 because of simple systems.

Therefore, the binary causal plane method formed by the combination of permutation entropy and SCM can characterize the efficiency of markets better. This method analyzes the market function from different perspectives and then takes the structure of real estate market into consideration. There is no doubt that more available market information is incorporated in this method. Zunino et al. [15] adopted this method to measure the efficiency of global major stock markets and found that this method could not only accurately identify the markets of developed and developing countries but also divide the markets of many countries into more categories, fully reflecting the discrimination ability of the model. Theoretically, the higher the complexity of a financial market is, the stronger the randomness and disorder of the market will be. At this time, the corresponding permutation entropy will be larger, that is, the permutation entropy is positively correlated with complexity. On the other hand, the higher the degree of disorder and chaos in the market is, the higher the probability that the market tends to be invalid is, that is, the permutation entropy is negatively correlated with the efficiency. Therefore, it can be considered that the complexity of the market is negatively correlated with its effectiveness through the transfer of permutation entropy (see Rosso et al. [29] and Shaobo et al. [30]).

\section{Empirical Analysis}

4.1. Data and Statistical Description. We initially take the 70 main cities defined by National Bureau of Statistics (NBS) as our research objects. Due to the lack of relevant data of Anqing, Dali, and Yangzhou, we finally select the remaining 67 cities as our research objects. To simplify the presentation, we number the cities from 1 to 67 according to the alphabetical order of cities. At the same time, the overall real estate market in China is also incorporated into our study and numbered as No. 68.

The data of each research unit used in the empirical test mainly involve three indicators: house price index (HPI), consumer price index (CPI), and per capita income index (PPI). We collect the data from Wind database and Chinese economic and social big data research platform. Considering the availability of the data, the time interval of the sample data spans from July 2005 to December 2017, and we have a total of 150 monthly samples. For convenience, we set the HPI in July 2015 as 100 points and treat it as the basis. Average monthly salary of residents is a proxy variable of PPI. As for the CPI, we set the CPI in July 2015 as 100 points and treat it as the basis, same as HPI. A few missing data are interpolated by linear interpolation.

Table 1 shows the simple descriptive statistics of HPI in Chinese overall real estate market. From Figure 1, we can see the specific trend of HPI from 2005 to 2017. Combined with Table 1 and Figure 1, the overall housing price in China presents an overall upward trend during the sample period. Chinese housing prices have risen about 1.7 times since July 2005 , with a monthly average growth rate of 0.0036 and an annual average growth rate of 0.0576 . Although the fluctuation of Chinese housing price is small on the whole, its fluctuation frequency is high. From July 2005 to the end of 2017, Chinese housing price experienced at least 7 fluctuations. Besides the role of market itself, most of these fluctuations are related to the government's regulation policies. There are several severe fluctuations that deserve attention. Affected by the global financial crisis in 2008, housing prices began to fall sharply in October 2008. However, with the issue of several stimulus policies of the government, housing prices began to recover and rise in April 2009, which led to the steady rise of housing prices in later three years. In 2011, many cities successively launched the control policies centering on the purchase restriction. In October 2011, the housing price dropped slightly. However, with the implementation of easy monetary policy in 2012 and the reduction of bank reserve ratio, the real estate 
TABLE 1: The simple descriptive statistics of HPI in Chinese overall real estate market.

\begin{tabular}{lcccccccc}
\hline Type & Max & Min & Mean & Median & Std & Skewness & Kurtosis & Monthly average growth rate \\
\hline China & 117.61 & 68.3 & 93.45 & 96.13 & 12.77 & -0.24 & 2.26 & 0.0036 \\
\hline
\end{tabular}

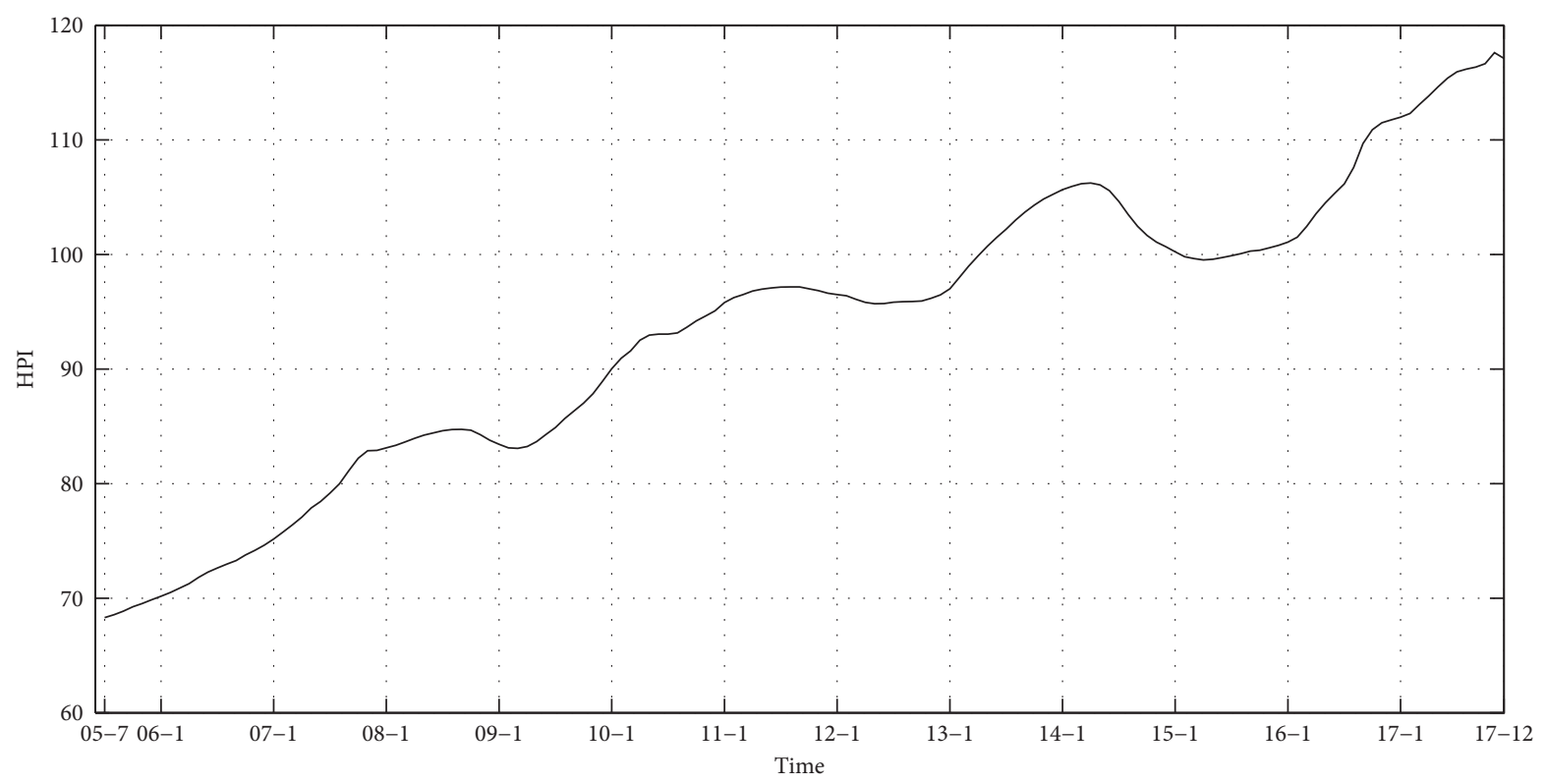

FIgURE 1: HPI trend of the overall real estate market.

market began a new growth period. In the latter half of 2014, the real estate market got into murky situation. This is due to the combined effect of regulatory policies and anticorruption efforts. But the new "330 policy" (a new real estate regulation and control policy on March 30, 2015) and the two interest-rate cuts in the latter half of 2015 initiated a wild rising tendency in a new round for housing prices. In 2016, due to the shortage of land, there was even a phenomenon that flour was more expensive than bread, which made the real estate market to be concerned again. In 2017, housing prices remained high, but the growth rate had been slower than that in 2016.

Considering the large amount of data, the basic descriptive statistics of HPI of 67 main cities cannot be fully presented due to space constraints. Here, we just demonstrate the HPI trend of each city, as shown in Figure 2.

As can be seen from Figure 2, housing prices in China had a rise tendency before 2015, but the tendency was moderate. It was after 2015 that severe fluctuations in housing prices occurred in many cities. From 2015 to 2016, housing prices soared rapidly, which was the fastest growth in the latest decade. Housing prices in many cities became relatively stable until 2017. In 67 cities, Wenzhou (No. 50) and Shenzhen (No. 44) are relatively special samples on studying the housing price. After the financial crisis in 2008, Chinese government launched " 4 trillion stimulus plan" to stimulate the economic recovery. In the first half of 2009, housing prices in Wenzhou took the lead in response and started a new round of surge. At that time, housing prices in Wenzhou were even far higher than the first-tier cities, leading the country. However, bubbles would burst sooner or later. Its housing prices declined steeply in the latter half of 2011. This price change lasted for more than 20 months. Then, a large number of investors and speculators withdrew from the property market. Although the government adjusted the purchase restriction policy, it achieved little success in saving the property market. In the next years, the property market was in a mild state until the appearance of property boom in 2016. Before 2015, Shenzhen real estate market compared with other first-tier cities seemed to be depressed, but after 2015, housing prices in Shenzhen rose rapidly and the increase was nearly $50 \%$ just in 2015. It is not only because of its strong ability to absorb population, resulting in huge housing demand, but also because of the government's deregulation policy, reducing the real estate market access threshold of residents.

4.2. Econometric Model Setup. We have mentioned that reasonable housing price in general equilibrium state is proportional to income. Therefore, if we take per capita income of residents as the independent variable and housing price index as the dependent variable, we can construct a linear econometric model as follows:

$$
p_{i t}=\alpha_{i}+\beta_{i} \mathrm{PPI}_{i t}+\varepsilon_{i t}
$$

where $i$ denotes the number of research object, $t$ denotes the time, $p_{i t}$ is the HPI of research object $i$ at given time $t, \mathrm{PPI}_{i t}$ is the corresponding average income, and $\varepsilon_{i t}$ is a random disturbance term. Based on the above theory, we just need to analyze the residual series $\varepsilon_{i t}$ to test the market efficiency.

Firstly, we carried out the regression analysis on collected data according to the established econometric model 


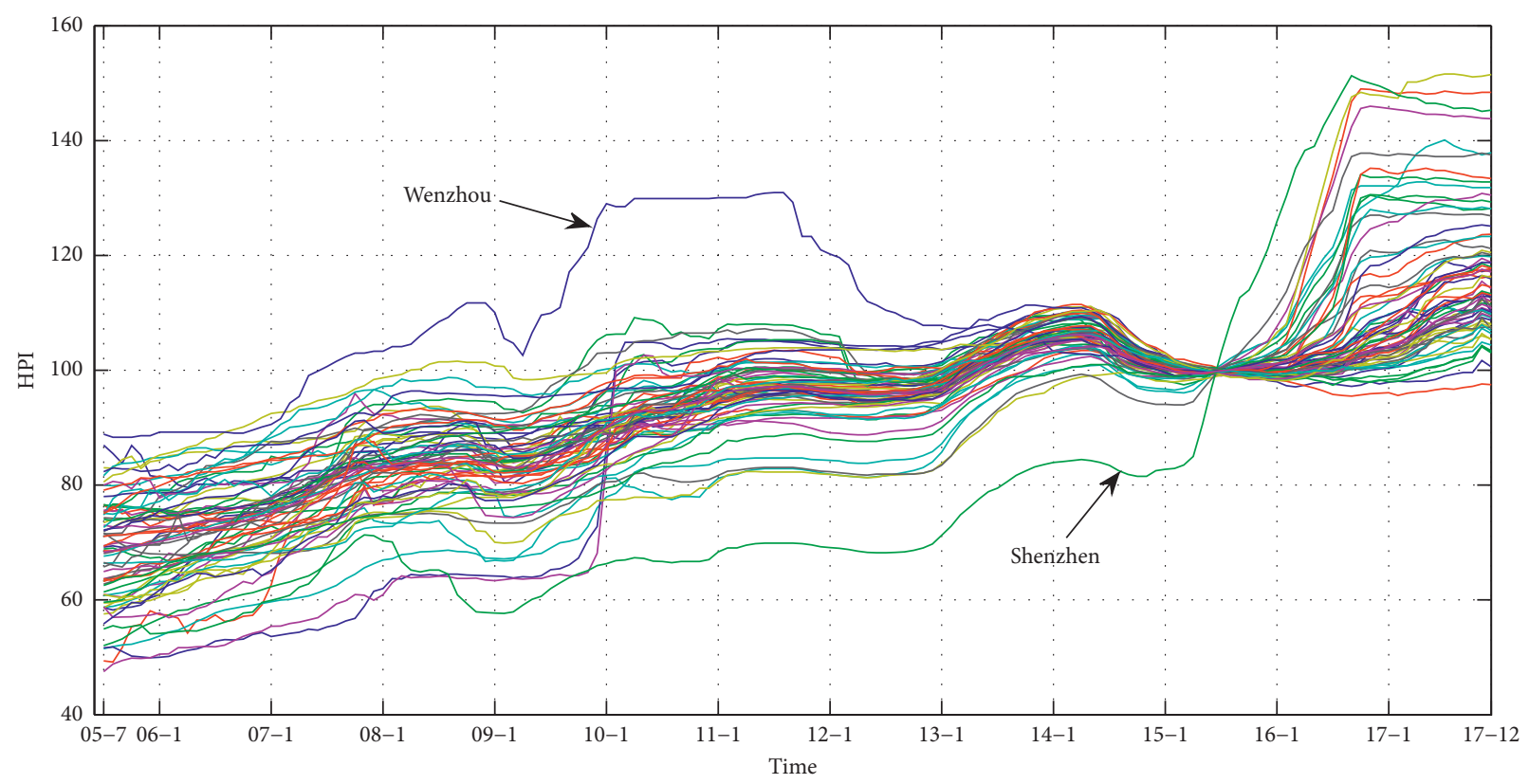

FIGURE 2: HPI trend of each city.

and then obtained regression coefficients and determination coefficients (also called goodness of fit), as shown in Figures 3 and 4 . The signs of regression coefficients in Figure 3 are all positive. The results show that HPI has positive correlation relationship with the PPI to some extent, but the correlation degree varies with cities. In most cities, the results of $t$-test aimed at regression coefficients are significant at the $1 \%$ confidence level, and the $p$ value approaches to 0 . However, the $t$-test results of 8 cities, including Guilin, Huizhou, Xiangyang and so on, cannot realize significance at the $10 \%$ confidence level. It is clear from Figure 4 that not all housing price indexes can be fitted well by per capita income of residents. As for most cities, the explanatory power is poor. There are 17 cities whose goodness of fit is even lower than $10 \%$, and the number of cities whose goodness of fit is higher than $50 \%$ is only 16 . It implies that PPI cannot account for most of the variations in HPI, which is not consistent with the feature of a rational real estate market. However, this irrational phenomenon is in line with Chinese current real estate development status. In other words, there exist house price bubbles. Only under the condition of deep marketization, the housing price is obviously proportional to the per capita income. But the government's intervention policies play an important role in leading to the fluctuations of housing prices nowadays, besides the market's spontaneous adjustment.

4.3. Efficiency Test. Based on the complexity-entropy binary causal plane method, the residual in model (16) is used as the bridge to test the efficiency of Chinese housing price. In the practical application, we make the delay time $\tau=1$ as usual. And it is suggested that the embedding dimension $D$ should satisfy $M \gg D$ !, where $M$ is the number of samples. In our study, $M=150$, so the embedding dimension can take 2, 3 ,
4, or 5. By comparison, we determine the optimal embedding dimension $D=5$. This process can be illustrated by Figure 5. There are different outcomes of 8 embedding dimensions as seen in Figure 5. When the dimension is gradually increased from 2 to 5 , the correlation between permutation entropy and complexity is still the same, that is, a negative correlation. However, when the embedding dimension $D$ is larger than 5 , the relationship between them is suddenly reversed, that is, a positive correlation. Therefore, it is valid to set $D=5$. In addition, as the embedding dimension changes, the degree of divergence for different points also changes. We can find that it can distinguish each state to the greatest extent at $D=5$, and the effect of remaining dimensions gradually declines, such as $D=2$ and $D=8$. It is shown on the graph that all points are concentrated in a narrow area. It is easy to explain this phenomenon. When the value of embedding dimension is small, there are few states. For example, there are only two states when $D=2$, which is naturally difficult to distinguish. In an extreme case, there is only one state when $D=1$, and the results of all states must be the same. It does not make any difference. On the other hand, when the value of embedding dimension is large, we can get a large number of states. For example, there is 40320 states when $D=8$, but we only have 150 samples. These samples can only touch a limited number of states. Other states are not accessible at all, which results in the poor performance of divergence. Also, this explains why $M \gg D$ ! is usually required.

After determining the optimal embedding dimension, we begin to calculate the complexity and efficiency of real estate markets. Table 2 shows the descriptive statistics of them.

For intuitive expression, we plot the results into a complexity-entropy binary causal plane. Figure 6 shows the complexity-efficiency binary map of 67 cities' real estate 


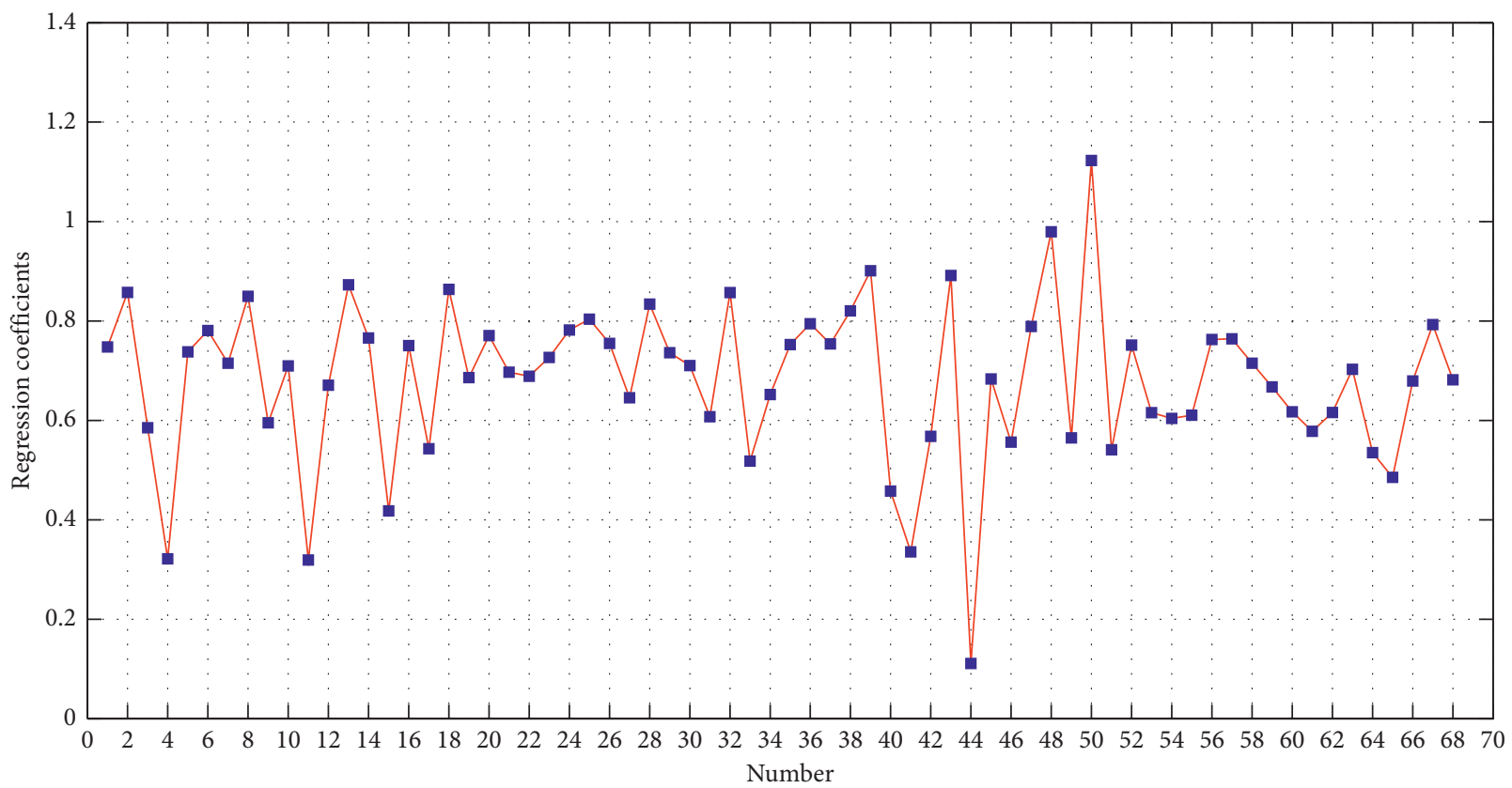

FIgURE 3: Regression coefficients $\beta$.

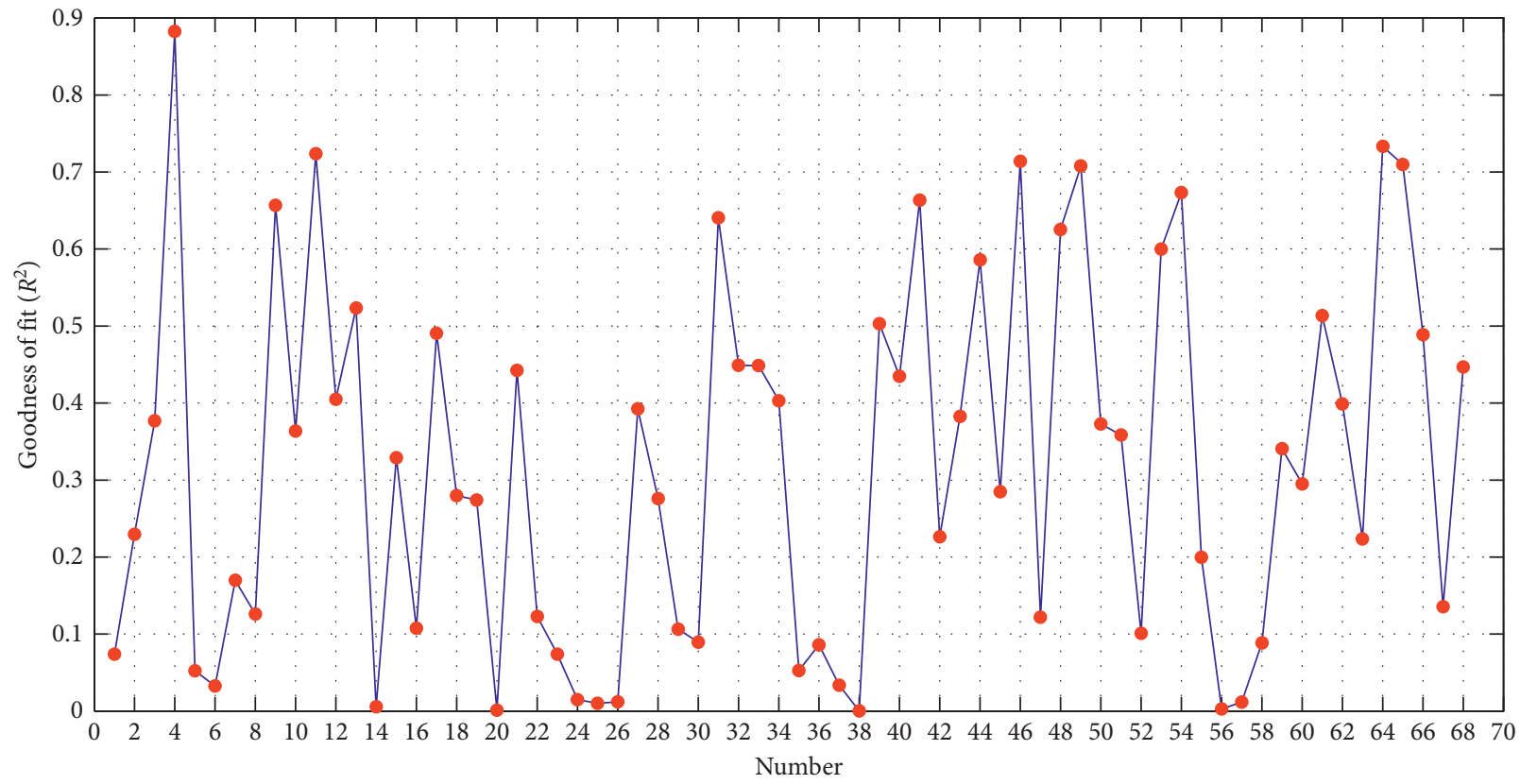

Figure 4: Goodness of fit $R^{2}$.

market. It can be found that there is higher efficiency and lower complexity at the lower right corner, in which the real estate market is more efficient and simpler. Otherwise, the market efficiency is low and the market structure is complex.

According to the empirical results, China does not have completely efficient real estate market, that is, no real estate market is completely random. The city with the highest efficiency in Chinese real estate market is Tangshan (No. 48), whose efficiency has been over 0.91 . Also, this city has the lowest complexity, which is only 0.103 . On the contrary, the real estate market of Shenzhen city (No. 44) is the least efficient and most complex. To further study the relationship between the efficiency and complexity of the real estate market, Table 3 lists the top 10 cities in four extreme cases. They are the most efficient, the least complex, the least efficient, and the most complex, respectively. It is easy to see from the cities listed in Table 3 that there is a significant relationship between the efficiency of real estate markets and the complexity of them.

Market efficiency indicator $H_{S}$ reflects whether the real estate market price can fully respond to the market information. It has been proved by our empirical test that the real 


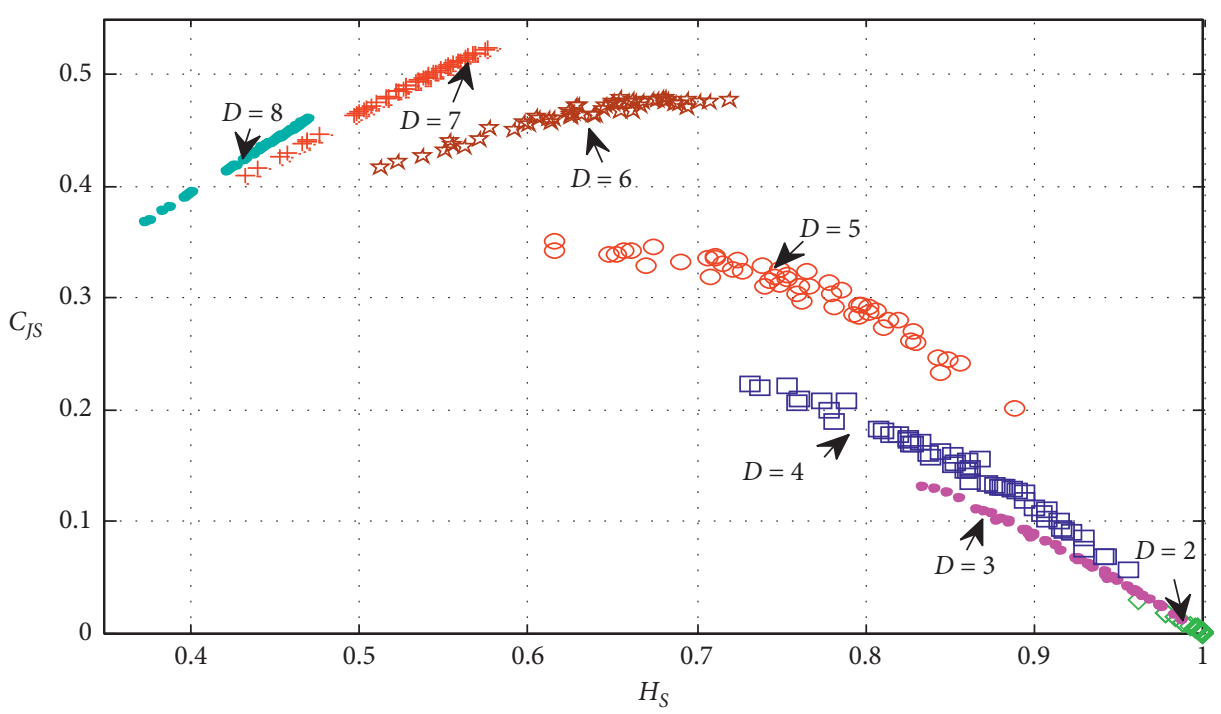

Figure 5: The selection of embedding dimension.

TABLE 2: The simple descriptive statistics of efficiency and complexity.

\begin{tabular}{lccccc}
\hline & Max & Min & Mean & Median & Std \\
\hline Efficiency $H_{S}$ & 0.9104 & 0.5906 & 0.7862 & 0.7924 & 0.0660 \\
Complexity $C_{J S}$ & 0.2753 & 0.1030 & 0.1994 & 0.2021 & 0.1030 \\
\hline
\end{tabular}

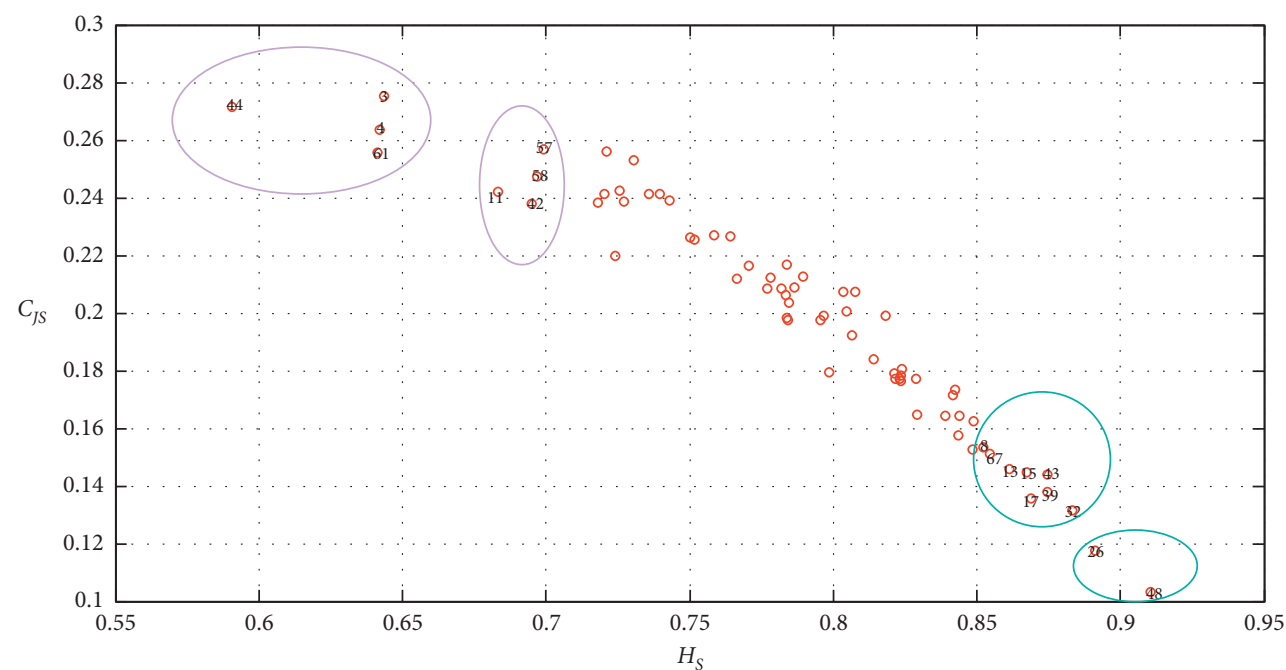

Figure 6: Complexity-entropy binary causal plane of Chinese real estate market.

estate markets of 67 main cities do not reach weak form efficiency, which implies that housing prices have a poor performance in responding to the market information and the liquidity of information is not enough. This is related to the nature of the real estate market. Compared with other capital markets, the real estate market has many unique characteristics, such as industrial barriers to entry, regional differences, vulnerable to policy, and housing heterogeneity. Also, there is a monopoly phenomenon in the land development rights. Under the function together with the aforementioned factors, there is less probability to form the housing price just by the complete market competition. The efficiency of market information transmission becomes low, so it cannot meet the requirements of a weak form effective market. Furthermore, it is much difficult to quickly make the market weakly effective and meet the basic housing needs of residents only by relying on the spontaneous regulation of market. Therefore, considering the importance of real estate market to the national economy and people's livelihood, it is indispensable for the government to implement some reasonable and effective regulation measures and policy guidance. 
TABle 3: Top 10 cities in four extreme cases in Chinese market.

\begin{tabular}{|c|c|}
\hline Features & Cities \\
\hline $\begin{array}{l}\text { Top } 10 \text { cities with the most efficient real estate } \\
\text { markets }\end{array}$ & $\begin{array}{c}\text { Tangshan (0.9104), Kunming (0.8913), Nanchong } \\
\text { (0.8833), Shao guan }(0.8747) \text {, Quanzhou (0.8746), } \\
\text { Hefei }(0.8691) \text {, Haikou (0.8675), Guilin }(0.8614) \text {, } \\
\text { Zunyi }(0.8545) \text {, and Dandong }(0.8522)\end{array}$ \\
\hline $\begin{array}{l}\text { Top } 10 \text { cities with the least complex real estate } \\
\text { markets }\end{array}$ & $\begin{array}{c}\text { Tangshan (0.1030), Kunming (0.1174), Nanchong } \\
(0.1316) \text {, Hefei }(0.1357) \text {, Quanzhou (0.1379), Shao } \\
\text { guan (0.1439), Haikou (0.1447), Guilin }(0.1460), \\
\text { Zunyi }(0.1511) \text {, and Dandong }(0.1526)\end{array}$ \\
\hline Top 10 cities with the least efficient real estate markets & $\begin{array}{c}\text { Shenzhen (0.5906), Yueyang (0.6415), Beijing } \\
(0.6420) \text {, Beihai (0.6437), Guangzhou (0.6831), } \\
\text { Shanghai (0.6951), Yantai (0.6968), Xuzhou (0.6992), } \\
\text { Jining (0.7180), and Xiamen (0.7203) }\end{array}$ \\
\hline $\begin{array}{l}\text { Top } 10 \text { cities with the most complex real estate } \\
\text { markets }\end{array}$ & $\begin{array}{c}\text { Beihai }(0.2735) \text {, Shenzhen }(0.2715) \text {, Beijing }(0.2635), \\
\text { Xuzhou }(0.2567) \text {, Yueyang }(0.2557) \text {, Huizhou } \\
(0.2532) \text {, Yantai }(0.2473) \text {, Wuhan }(0.2424), \\
\text { Guangzhou }(0.2421) \text {, and Jinan }(0.2413)\end{array}$ \\
\hline
\end{tabular}

The market complexity indicator $C_{J S}$ represents the complexity of the market structure itself. There are always multilevel markets or various factors affecting the market price, especially nonmarket factors derived from government intervention. It has been illustrated by the complexity of real estate markets in main Chinese cities. Cities with a relatively complex real estate market structure in China are mainly concentrated in first-tier cities, represented by Beijing, Shanghai, Guangzhou, and Shenzhen. These cities have more advantageous resources, thus leading to a massive influx of population and then forming a sharp expansion of housing demand and pushing housing prices further. At this time, the spontaneous regulation of the market could not meet the needs of residents. In order to coordinate the unbalanced allocation of resources and stabilize social development, the government has to take a series of regulation measures, which increased the complexity of the market structure inevitably. As for those less developed cities, the complexity of their real estate market structures is relatively low because of stable supply and demand relationship, better spontaneous regulation ability, and less government intervention. The lower $C_{J S}$ is, the simpler the market structure is and the easier it is to be improved. Conversely, the more complex the market structure is, the more difficult it is to be governed. For the market with complex structure, it is necessary to analyze different factors more comprehensively and take targeted combination measures. Generally, market efficiency is highly correlated with complexity, but not always. The previous empirical results have revealed this point. Due to the disadvantages brought by complexity market structure, it is more difficult to deal with the higher complexity market when the degree of efficiency is at the same level.

4.4. Efficiency Comparison of Chinese and American Real Estate Markets. The development of American real estate market has gone through many years, most of which was relatively stable and made great contributions to the healthy and rapid development of American economy. Moreover,
American market has experienced a huge crisis, especially the global financial crisis caused by the burst of the real estate bubble in 2007. After the crisis, the real estate was still an important engine of economic growth in America. With the recovery of American economy, the real estate industry also took a turn for the better. From the perspective of economic cycle, the development of the real estate market in the United States has gone through a complete economic cycle. Moreover, the housing system of the United States was recognized as a relatively successful system by housing experts from all over the world at that time [31]. The United States adopted government intervention, but did not "take all risks." It not only had appropriate social security of the government but also made the residents do their best to afford housing consumption.

Although the national conditions and economic development stages are obviously different, China and United States are both big countries, and there is heterogeneity of development between different cities or regions. After the reform and opening up in 1978, China took the road of unbalanced development and adopted the development strategy of "give priority to supporting the development of the eastern coastal areas." After years of development and accumulation, this strategy directly led to the regional imbalance of economy among the central, western, and eastern regions. Even in the same region, regional central cities and other noncentral cities have differences. Compared with the noncentral city, the central city gathers more resources and capital, promotes the development of local economy, attracts more people to gather in the central city, and improves the local house price. This is the same in China and the United States. Song and Gao [32] pointed out that due to the influence of geographical factors and economic development level, the American housing price growth of nine regions divided by the federal real estate industry monitoring office had huge difference, even among different states in the same region. However, even in this unbalanced development situation, the real estate industry in the United States has become the driving force of economic growth, while providing sufficient social security. Therefore, it has important 


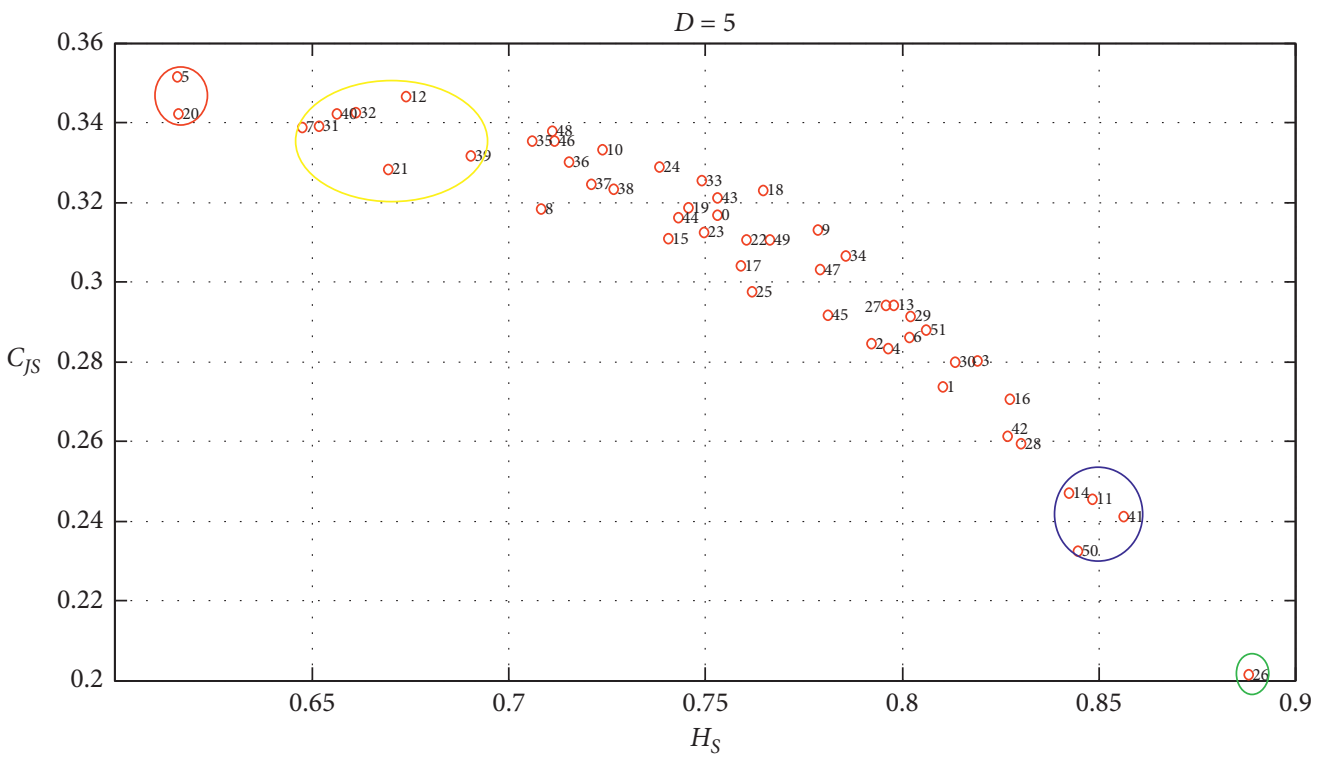

FIGURE 7: Complexity-entropy binary causal plane of American real estate market.

TABLe 4: Top 10 states in four extreme cases in American market.

\begin{tabular}{lc}
\hline Features & States \\
$\begin{array}{l}\text { Top } 10 \text { states with the most efficient real estate } \\
\text { markets }\end{array}$ & $\begin{array}{c}\text { Mississippi, South Carolina, Georgia, West Virginia, } \\
\text { Idaho, North Carolina, Indiana, South Dakota, } \\
\text { Arkansas, and Nebraska }\end{array}$ \\
\hline $\begin{array}{l}\text { Top } 10 \text { states with the least complex real estate } \\
\text { markets }\end{array}$ & $\begin{array}{c}\text { Mississippi, West Virginia, South Carolina, Georgia, } \\
\text { Idaho, North Carolina, South Dakota, Alaska, and } \\
\text { Nebraska }\end{array}$ \\
$\begin{array}{l}\text { Top } 10 \text { states with the least efficient real estate } \\
\text { markets }\end{array}$ & $\begin{array}{c}\text { California, Massachusetts, Connecticut, New } \\
\text { Hampshire, Rhode Island, New Jersey, Maryland, } \\
\text { Top } 10 \text { states with the most complex real estate } \\
\text { markets }\end{array}$ \\
\hline
\end{tabular}

reference and warning value for Chinese real estate industry if we take it as the object of comparative study.

In order to study the efficiency of the American real estate market, we select 50 states and the District of Columbia as our research objects. Similar to China, we also studied the efficiency of American overall real estate market. We collected relevant data from the first quarter of 1975 to the first quarter of 2014, summing up to 157 quarters. Individual missing data were supplemented by linear interpolation, and we made seasonal adjustments to eliminate the influence of seasonal factors. Using the same econometric model and test method, we obtained the efficiency and complexity of American real estate market. As can be seen from Figure 7, the real estate market of each state and the overall market in America have not reached a weak efficient state, which is the same as China.

The state with the highest degree of efficiency in American real estate market is Mississippi, whose efficiency reaches 0.886 , while its complexity is only 0.201 at the lowest complexity level in America. On the other hand, the state with the least efficient and most complex real estate market is
California. Its efficiency and complexity are 0.616 and 0.352 , respectively. The significant negative correlation between the efficiency and the complexity in American market is consistent with that in Chinese market. To further illustrate the relationship between efficiency and complexity, Table 4 shows the top 10 states in four extreme cases in American real estate market.

Combined with Tables 3 and 4, it can be seen that the relationship between the efficiency of the real estate market and the level of regional economic development in China is contradictory to that in America. In China, those cities with high efficiency and low efficiency are most of the third-tier or below cities, such as Tangshan (No. 48), Shao guan (No. 43), Guilin (No. 13), Zunyi (No. 67), and so on. The first-tier or second-tier cities with developed economy and high comprehensive level are always less efficient and more complex in real estate market, such as Shenzhen (No. 44), Beijing (No. 4), Guangzhou (No. 11), Xuzhou (No. 57), and so on. As for the United States, it is just the opposite. Those states with higher efficiency and lower complexity are mostly located in the east and west coasts, such as Mississippi (No. 26), South 
Carolina (No. 41), Georgia (No. 11), West Virginia (No. 50), and northern Idaho (No. 14). These states all belong to the area whose economy is relatively developed and population is dense. The less efficient areas are located in the middle of the United States and with poor economy. So how to ensure the efficiency and orderliness of the real estate market while developing the economy is what we can learn from the United States.

From the perspective of the relationship between the efficiency and complexity of the real estate market, the performance of Chinese market is consistent with that of American market. It can be seen from Tables 3 and 4 that cities with higher efficiency tend to have lower complexity, and the ranking order is almost the same. In order to clarify the generality of this correlation, we rank the efficiency and complexity and calculate their Spearman order statistical correlation coefficient. Then, we obtain the rank correlation coefficient of efficiency and complexity of Chinese real estate market and American real estate market. The correlation coefficients are -0.975 and -0.966 , respectively, which explains the obvious negative correlation between the efficiency and complexity of the real estate market well.

\section{Conclusions and Suggestions}

By the complexity-entropy binary causal plane method, we measure the efficiency and complexity of Chinese and American real estate markets. Our conclusions can be summarized as follows:

(1) Neither 67 main cities' real estate markets in China nor the overall real estate market has reached weak form efficiency. Both the efficiency and complexity vary with each subject. There is significantly negative correlation relationship between the degree of efficiency and complexity because their Spearman rank correlation coefficient has reached -0.975 . In Chinese cities, those with a high efficiency degree of real estate market are generally second-tier, third-tier, and lower cities, while those with a relatively developed economy such as Beijing, Shanghai, Shenzhen, and Guangzhou show a lower efficiency degree of real estate market and a higher complexity degree.

(2) The market efficiency and complexity of the United States are similar to that of China. Specifically, the real estate market in all states and the overall American market have not reached weak form efficiency. The Spearman rank correlation coefficient between the efficiency and complexity is -0.966 , showing the significant negative correlation. Different from China, the areas with high efficiency degree of American real estate market are basically located in the east and west coasts which are relatively developed and densely populated. On the contrary, the areas with low efficiency are located in the middle with relatively low level of economic development. Moreover, American real estate market is about as efficient as Chinese, but significantly more complex.

Combining the development history of American and Chinese housing finance, it can be found that housing price fluctuation of both countries has close relationship with the enforcement of some housing finance policies. For example, the irrational surges of housing prices over a period are mostly due to the government's efforts to stimulate the economy. Those interventions from government can lead to an excessive prosperity of the real estate market. From the perspective of policy connotation, the more efficient the market is, the less the government's intervention is. The lower degree of efficiency implies the less freedom of the market. In detail, some systems or rules set by the government affect the market's independent regulation. Therefore, on the one hand, it is necessary to formulate and implement some innovative regulation policies to guide the development of real estate market; on the other hand, it is required to find out the deficiencies of the current relevant policies and systems and then improve them. According to the conclusions of our study and the achievements of the housing price control policies issued by Chinese and American governments over the years, we put forward following suggestions to improve the efficiency of the real estate market in China:

(1) The government should improve mechanisms to enhance information transparency of the real estate market. If the real estate market is efficient, prices can respond adequately and quickly to other market information. At present, all main cities and the overall real estate market in China have not reached weak form efficiency. This phenomenon indicates that there is information asymmetry in the market and the information transmission mechanism among investors, sellers, and buyers is not perfect. The government can make more detailed rules to help information disclosure in the process of real estate transactions, so as to guarantee the liquidity, accuracy, and timeliness of information. Furthermore, it can reduce the information search cost, guide rational investment, and reduce the possibility of releasing false information by developers and speculators. Only in this way, we can ensure fair real estate market transaction and establish an information disclosure mechanism with openness, fairness, and impartiality to promote the healthy development of housing industry.

(2) The government should advocate both renting a house and buying a house to live in so as to promote the establishment of multilevel housing system. In some developed countries, such as Germany, the rental rate is as high as $58 \%$, but most residents still can live and work happily. The supply of a large number of rental housing has not only increased the well-being of residents but also played an important role in maintaining social stability. This harmonious 
phenomenon is inseparable from the perfect rental management system. As for China, there is large population, which results in strong demand for houses. However, because of the high housing price, many people, especially those young people freshly entering the workplace, cannot afford to buy own houses and have no choice but to rent a house. In order to meet the housing needs of low-income groups and maintain the healthy development of housing economy, policy guarantee should be accompanied by legislative regulation. Drawing on the classification supply system of the United States, the government should move faster to put in place a housing system that ensures supply through multiple sources, provides housing support through multiple channels, and encourages both housing purchase and renting. This will make us better placed to meet the housing needs of all of our people.

(3) The government should take targeted and differentiated measures. In the light of the empirical validation results in 67 cities, the efficiency degree and complexity degree of the real estate market vary from cities. Therefore, the regulation of real estate market in each city cannot be treated as the same; the government should take these factors into consideration, such as economic level, institutional environment, resource allocation, and the supply and demand of urban residents. Targeted and differentiated measures can play the role of regulating housing prices and stabilizing the market more effectively. For instance, there is a big difference in the housing inventory between the first- or second-tier cities and the third- or fourth-tier cities in China. For the third-and fourth-tier cities, destocking should be emphasized, while the first- and second-tier cities should actively prevent the risk of real estate bubble.

(4) The government should strengthen early monitoring and warning and then prevent international financial risks. In the context of economic globalization, changes in the international situation or the economic situation of a certain country often affect all over the world. Chinese trade with other countries has become increasingly close, and it is more impossible to stay independent. It is memorable that the trade war between Japan and the United States made a rapid rise in the yen over 2 decades ago. To tackle this crisis, the Japanese government decided to implement easy monetary policy and encourage local residents to invest real estate industry, making Japanese economy grow with bubbles. Finally, the burst of the bubble economy not only led to the Japanese house prices to decline dramatically but also caused the Japanese economy to collapse. We can learn from this trade war that we should pay close attention to foreign exchange risks, actively guard against the exchange rate risks caused by foreign capital inflow and domestic capital outflow, and strengthen risk early warning so as to prevent and tackle risks timely.

\section{Appendix}

The software applied to our work is MATLAB.

The syntax about how to calculate the permutation entropy and statistical complexity measure is presented as follows:

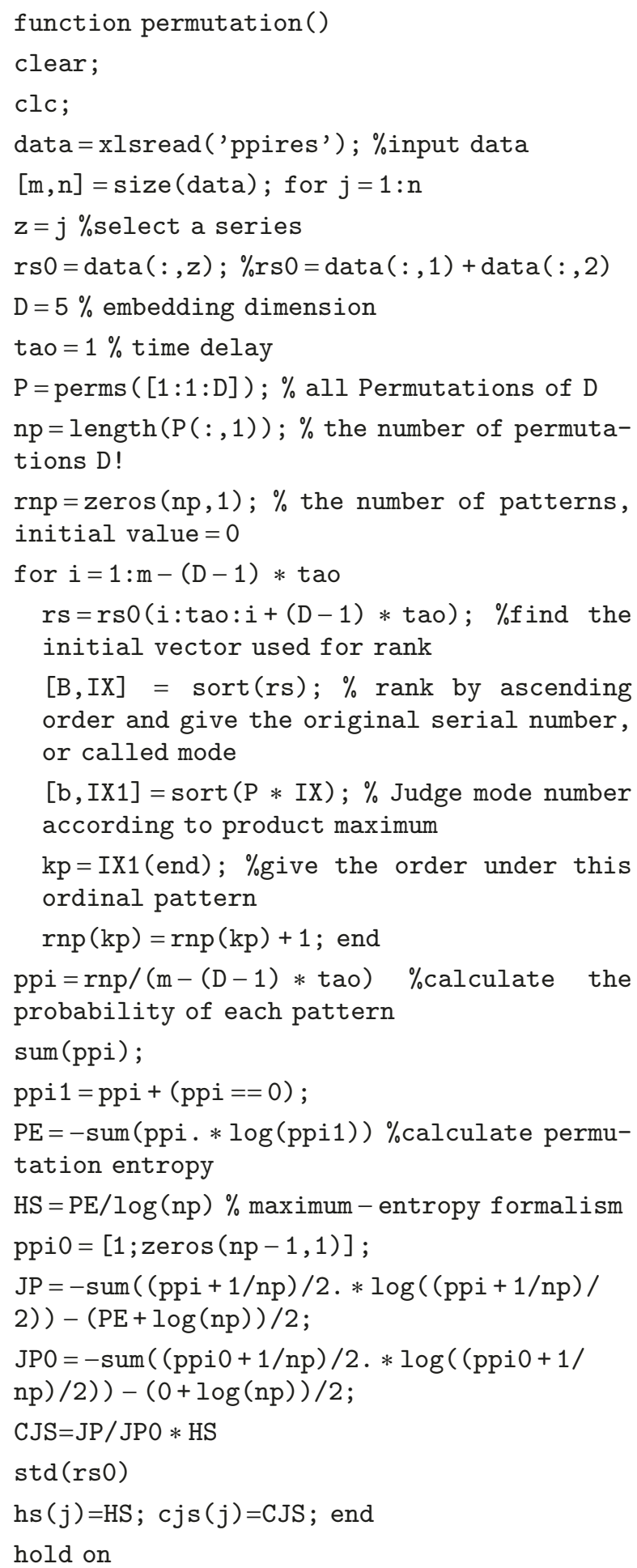


box on

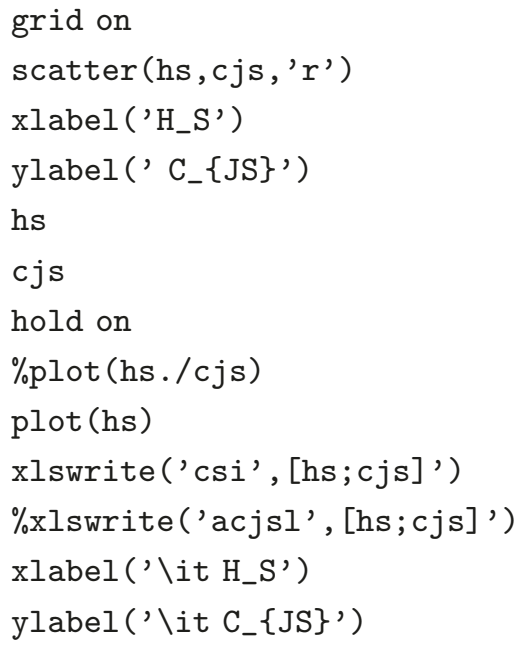

\section{Data Availability}

The data used to support the findings of this study are available from the Wind database, Chinese economic and social big data research platform, Federal Reserve System $(\mathrm{H})$, All-America Economic Survey, and the Bureau of Economic Analysis.

\section{Conflicts of Interest}

The authors declare that they have no conflicts of interest regarding the publication of this paper.

\section{Acknowledgments}

This work was supported by the Humanities and Social Science Planning Fund from Ministry of Education (16YJAZH078), the Fundamental Research Funds for the Central Universities of China (grant nos. CCNU19TS062, CCNU19A06043, and CCNU19TD006), and the raising initial capital for High-Level Talents of Central China Normal University (30101190001).

\section{References}

[1] R. Meese and N. Wallace, "Testing the present value relation for housing prices: should I leave my house in san Francisco?," Journal of Urban Economics, vol. 35, no. 3, pp. 245-266, 1994.

[2] J. Clayton, "Are housing price cycles driven by irrational expectations," The Journal of Real Estate Finance and Economics, vol. 14, no. 3, pp. 341-363, 1997.

[3] K. E. Case and R. J. Shiller, "Forecasting prices and excess returns in the housing market," Real Estate Economics, vol. 18, no. 3, pp. 253-273, 1990.

[4] J. M. Abraham and P. H. Hendershott, "Bubbles in metropolitan real estate markets," NBRE Working Papers, vol. 7, no. 35, pp. 171-192, 1994.

[5] S. R. Grenadier, "The persistence of real estate cycles," The Journal of Real Estate Finance and Economics, vol. 10, no. 2, pp. 95-119, 1995.
[6] P. Kunzel, Inefficienciesh in the Real Estate: Implications for the Price Dynamics, Ph.D. dissertation, The George Washington University, Washington, DC, USA, 2004.

[7] K. Wang, Y. Zheng, and H. Liu, "Review of the efficiency of real estate market in China," China Land Science, vol. 20, no. 5, pp. 54-59, 2006.

[8] L. Xie, Empirical Research on the Efficiency of Shanghai Real Estate Market, East China Normal University, Shanghai, China, 2014.

[9] A. Pan and H. Wang, "Inefficiencies of the real estate market in China: theory and empirical analysis," Finance and Economics, vol. 7, pp. 55-63, 2008.

[10] Q. Meng and R. Chen, "On real estate price bubbles of China: an empirical study based on Markov switching model," Financial Research, vol. 2, pp. 105-120, 2017.

[11] K. Guo and Y. Huang, "Problems and solutions of China's real estate market development on international comparisons," Finance\&Trade Economics, vol. 1, pp. 5-22, 2018.

[12] C. Chen, "Theoretical and practical analysis of the ratio of house price to income," Times Finance, vol. 5, pp. 18-20, 2014.

[13] K. E. Case and R. J. Shiller, "Is there a bubble in the housing market?," Brookings Papers on Economic Activity, vol. 2003, no. 2, pp. 299-362, 2003.

[14] L. Zunino, M. Zanin, O. A. Pérez, D. G. Pérez, and O. A. Rosso, "Forbidden patterns, permutation entropy and stock market inefficiency," Physica A: Statistical Mechanics and Its Applications, vol. 388, no. 14, pp. 2854-2864, 2009.

[15] L. Zunino, M. Zanin, B. M. Tabak, D. G. Pérez, and O. A. Rosso, "Complexity-entropy causality plane: a useful approach to quantify the stock market inefficiency," Physica A: Statistical Mechanics and its Applications, vol. 389, no. 9, pp. 1891-1901, 2010.

[16] O. A. Rosso, H. A. Larrondo, M. T. Martin et al., "Distinguishing noise from chaos," Physical Review Letters, vol. 99, no. 15, Article ID 154102, 2007.

[17] L. Gulko, "The entropic market hypothesis," International Journal of Theoretical and Applied Finance, vol. 2, no. 3, pp. 293-329, 1999.

[18] D. Matesanz and G. J. Ortega, "A (econophysics) note on volatility in exchange rate time series," International Journal of Modern Physics C, vol. 19, no. 7, pp. 1095-1103, 2008.

[19] W. A. Risso, "The role of the informational efficiency in the dotcom bubble," Social Science Electronic Publishing, vol. 17, no. 5, pp. 373-380, 2008.

[20] C. Bandt and B. Pompe, "Permutation entropy:a natural complexity measure for time series," Physical Review Letters, vol. 88, no. 17, Article ID 174102, 2002.

[21] M. Riedl, N. A. Müller, and N. Wessel, "Practical considerations of permutation entropy," The European Physical Journal Special Topics, vol. 222, no. 2, pp. 249-262, 2013.

[22] A. Ortiz-Cruz, E. Rodriguez, and C. J. Alvarez-Ramirez, "Efficiency of crude oil markets: evidences from informational entropy analysis," Energy Policy, vol. 41, pp. 365-373, 2012.

[23] G. Oh, S. Kim, and C. Eom, "Market efficiency in foreign exchange markets," Physica A: Statistical Mechanics and its Applications, vol. 382, no. 1, pp. 209-212, 2007.

[24] M. Staniek and K. Lehnertz, "Parameter selection for permutation entropy measurements," International Journal of Bifurcation and Chaos, vol. 17, no. 10, pp. 3729-3733, 2007.

[25] M. Matilla-García and M. Ruiz Marín, "Detection of nonlinear structure in time series," Economics Letters, vol. 105, no. 1, pp. 1-6, 2009.

[26] L. Faes, A. Porta, M. Javorka et al., "Efficient computation of multiscale entropy over short biomedical time series based on 
linear state-space models," Complexity, vol. 2017, Article ID 1768264, 13 pages, 2017.

[27] Z. Chen, Y. Li, H. Liang et al., "Improved permutation entropy for measuring complexity of time series under noisy condition," Complexity, vol. 2019, Article ID 1403829, 12 pages, 2019.

[28] P. W. Lamberti, M. T. Martin, A. Plastino, and O. A., "Intensive entropic non-triviality measure," Physica A: Statistical Mechanics and Its Applications, vol. 334, no. 1-2, pp. 119-131, 2004.

[29] D. Rosso, M. Varela-Entrecanales, A. Molina-Pico et al., "Patterns with equal values in permutation entropy: do they really matter for biosignal classification?," Complexity, vol. 2018, Article ID 1324696, 15 pages, 2018.

[30] H. Shaobo, S. Kehui, and W. Huihai, "Modified multiscale permutation entropy algorithm and its application for multiscroll chaotic systems," Complexity, vol. 21, no. 5, pp. 52-58, 2016.

[31] Q. $\mathrm{Wu}$, "Referring international experience to rationalize China's housing development ideas," Economic Issues, vol. 28, no. 2, pp. 13-15, 2006.

[32] Y. Song and L. Gao, "The prosperity and risk of American real estate industry and its impact on American economy," American Studies, vol. 20, no. 3, pp. 65-76, 2006. 


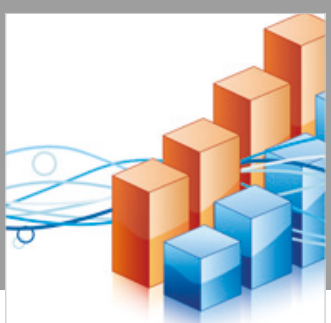

Advances in

Operations Research

\section{-n-m}
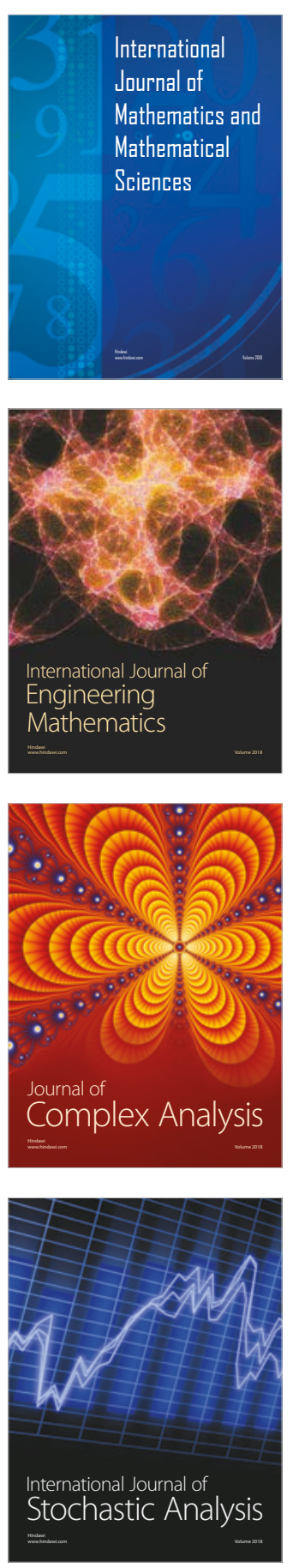
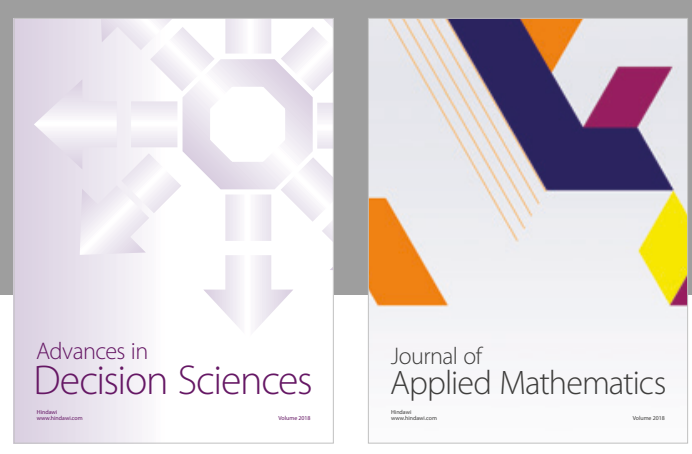

Journal of

Applied Mathematics
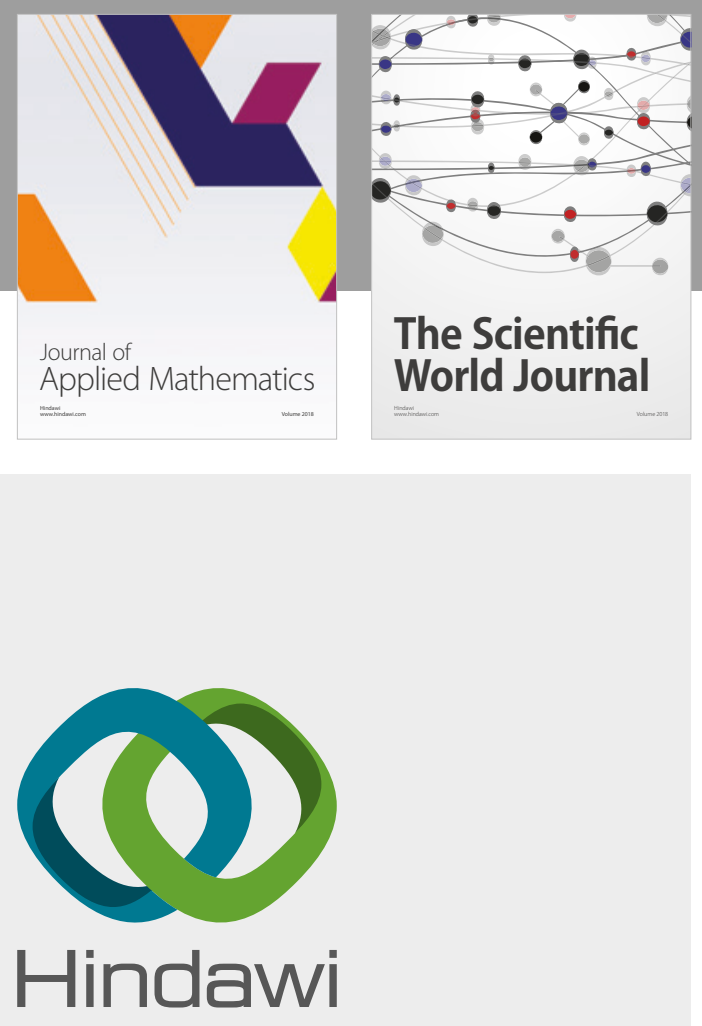

Submit your manuscripts at

www.hindawi.com

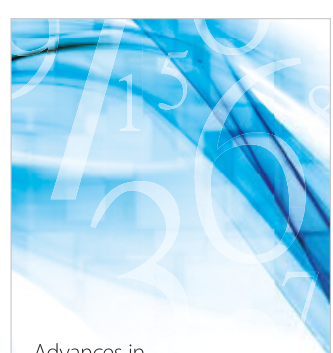

Advances in
Numerical Analysis
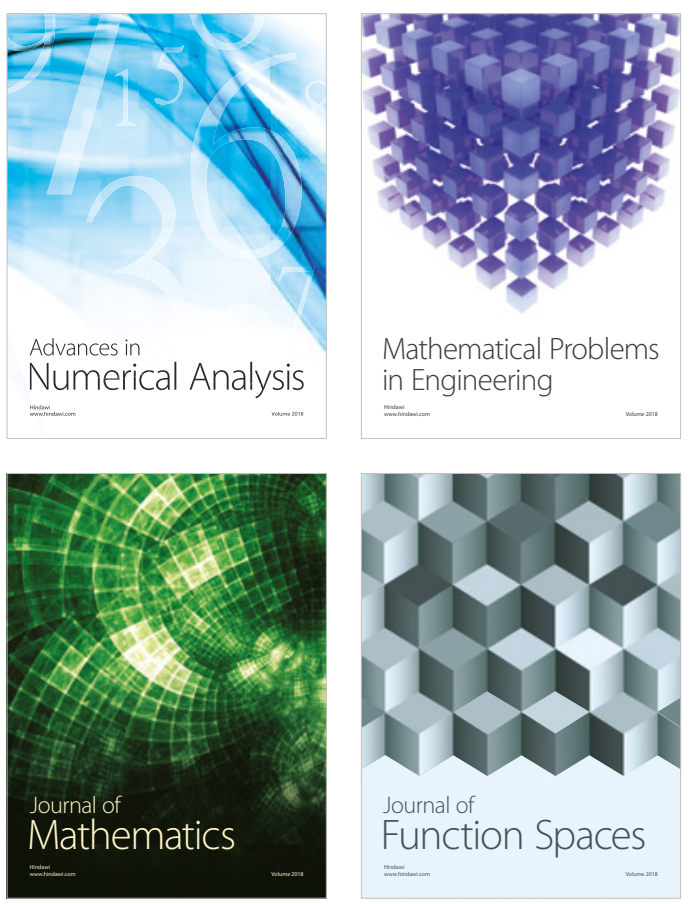

Mathematical Problems in Engineering

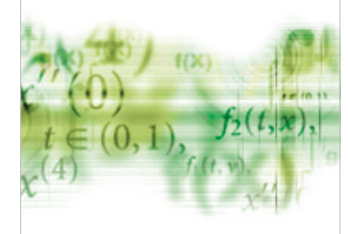

International Journal of

Differential Equations

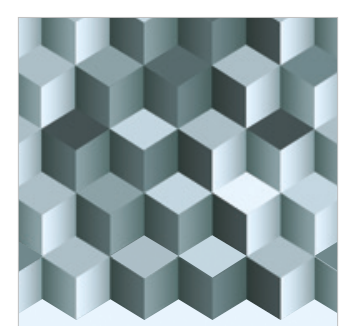

Journal of

Function Spaces
The Scientific

World Journal

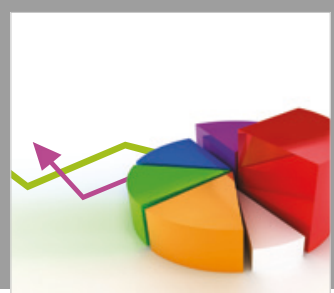

Journal of

Probability and Statistics
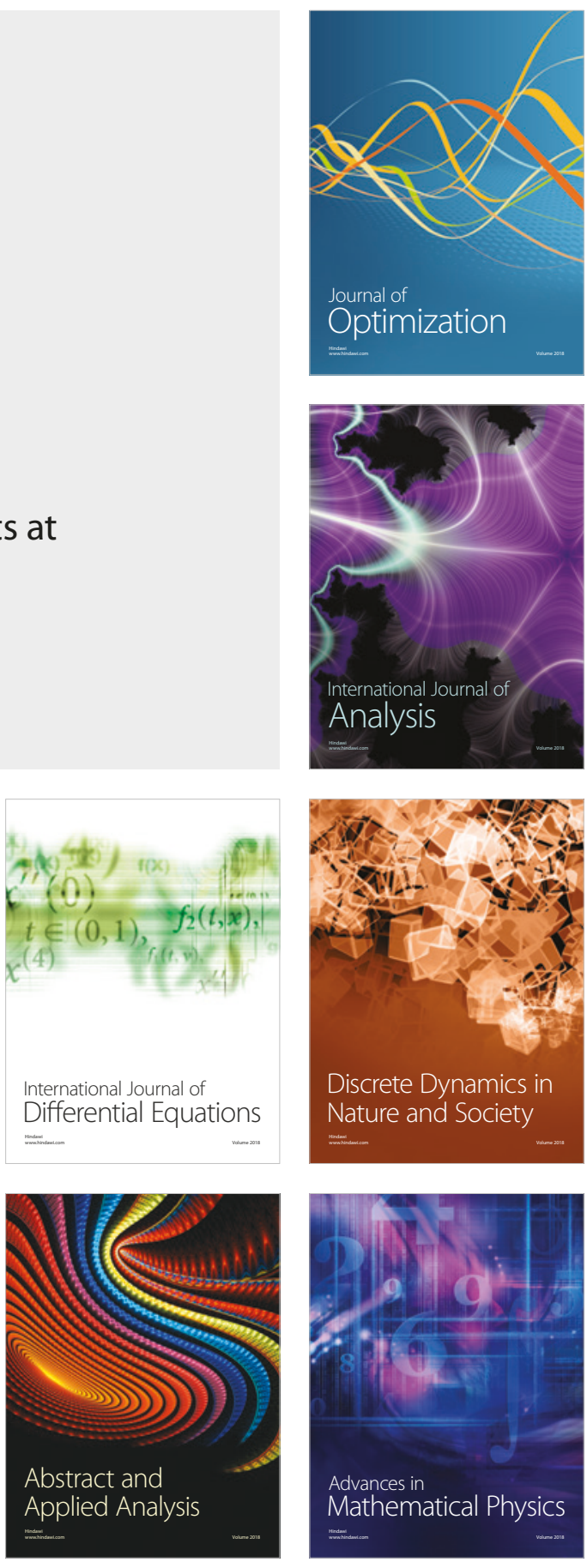